\title{
Blood antioxidant profile and lipid peroxides in dairy cows with clinical mastitis
}

\author{
Ricky J hambh, Umesh Dimri, Vinod Kumar Gupta and Rajesh Rathore
}

Division of Medicine, Indian Veterinary Research Institute, Izatnagar - 243122, Dist. Bareilly (U.P.) India

1. Centre for Animal Disease and Research, Indian Veterinary Research Institute, I zatnagar - 243122, Dist. Bareilly

(U.P.) IndiaCorresponding author: Ricky Jhambh, email: jhambricky@gmail.com

Received: 28-08-2012, Accepted: 17-09-2012, Published online: 07-02-2013

\section{How to cite this article:}

J hambh R, Dimri U, Gupta VK and Rathore R (2013) Blood antioxidant profile and lipid peroxides in dairy cows with clinical mastitis, Vet. World 6(5):271-273, doi: 10.5455/vetworld.2013.271-273

\begin{abstract}
Aim: To evaluate blood antioxidant profile and lipid peroxides in dairy cows with clinical mastitis.

Materials and Methods: Twelve cases of clinical mastitis in cross-bred cows were selected based on physical examination of udder and milk, California Mastitis Test (CMT), Somatic Cell Count (SCC) and confirmation by bacteriological examination of milk and requisite biochemical tests. Twelve lactating cows showing negative CMT reaction and SCC $<2 \times 10^{5}$ cells $/ \mathrm{ml}^{\mathrm{w}} \mathrm{were}$ considered as healthy control. Antioxidant parameters measured in blood were superoxide dismutase (SOD), catalase activities and reduced glutathione (GSH) concentration. Erythrocytic lipid peroxidation (LPO) was measured in terms of malondialdehyde (MDA) production.
\end{abstract}

Results: Significant $(P<0.05)$ decrease in blood SOD and catalase activities, GSH concentration and an increase in erythrocytic lipid peroxides was observed in cows with clinical mastitis.

Conclusion: It is concluded that there is a compromise in antioxidant defense of the body in dairy cows with clinical mastitis resulting in oxidative damage, therefore, necessitate the use of antioxidants and other protective compounds along with conventional therapy for mastitis control.

Keywords: catalase, clinical mastitis, dairy cows, glutathione, lipid peroxides, superoxide dismutase

\section{I ntroduction}

Cells living under aerobic environment are continuously exposed to number of oxidants derived from various endogenous and exogenous sources [1]. Under normal physiological conditions, antioxidant defense system within the body can effectively neutralize the oxidants produced. When the production of oxidants exceeds the capacity of antioxidant defense, a condition of oxidative stress is produced resulting in oxidative damage to macromolecules such as lipids, DNA and proteins [2]. The oxidative stress may be involved in several pathological conditions including mastitis in dairy animals $[3,4]$ which is characterized by an influx of somatic cells, primarily the neutrophils, into the mammary gland. These neutrophils destroy the invading bacteria by oxygen-dependent and oxygenindependent systems. Simultaneously, they potentially damage the secretory epithelium of mammary gland by reactive oxygen species and proteolytic enzymes, resulting in decreased milk production [5]. Although, there are evidences that inflammation of mammary gland may alter the blood oxidative stress parameters in terms of lipid peroxides, reduced glutathione (GSH), vitamin $A, C, E$ and trace elements [6,7] but the information on enzymatic antioxidants such as superoxide dismutase (SOD), catalase (CAT) which are the most efficient in directly catalyzing reduction of reactive oxygen species [2] in mastitis is still scanty.
Therefore, the present study was carried out to evaluate blood antioxidant profile and lipid peroxides in dairy cows with clinical mastitis.

\section{Materials and Methods}

Selection of animals: The study was carried out in cross-bred dairy cows (Haryana x Jersey/Brown Swiss/Holstein Friesian) maintained under identical feeding and management practices at the Cattle and Buffalo farm, Livestock Production and Management section, Indian Veterinary Research Institute, Izatnagar, India. Twelve cases of acute clinical mastitis were selected based on physical examination of udder and milk collected in sterile glass vials. The udder and teats of cows were examined for signs of inflammation i.e. redness, swelling, warmth, pain and depressed function. The quarters with any physical deformity like atrophy or fibrosis, blind or supranumerary teats etc. were excluded from the study. The milk was examined for the presence of discoloration, blood clots, flakes, purulent material etc. The milk samples were also examined for somatic cell count (SCC) indirectly by California Mastitis Test (CMT) as per Schlam and Noorlander [8] and directly as per Schlam et al. [9]. Further confirmation of intramammary infection was done by bacteriological examination of milk and requisite biochemical tests [10]. Twelve lactating cows showing negative CMT reaction and $\mathrm{SCC}<2 \times 10^{5}$ 
Table-1. Blood antioxidant profile and lipid peroxides in dairy cows with clinical mastitis (Mean \pm S.E.)

\begin{tabular}{lll}
\hline Parameter & Healthy control & Clinical mastitis \\
\hline SOD $(\mu \mathrm{mol} \mathrm{MTT} \mathrm{formazan} / \mathrm{mg} \mathrm{Hb})$ & $0.577 \pm 0.007^{\mathrm{a}}$ & $0.450 \pm 0.003^{\mathrm{b}}$ \\
CAT $\left(\mu \mathrm{mol} \mathrm{H} \mathrm{O}_{2}\right.$ decomposed/min/mg Hb) & $180.53 \pm 3.77^{\mathrm{a}}$ & $71.16 \pm 1.41^{\mathrm{b}}$ \\
GSH $(\mu \mathrm{mol}$ conjugate/ml packed RBC) & $0.109 \pm 0.009^{\mathrm{a}}$ & $0.069 \pm 0.003^{\mathrm{b}}$ \\
LPO $(\mathrm{nmol} \mathrm{MDA} / \mathrm{mg} \mathrm{Hb})$ & $2.473 \pm 0.061^{\mathrm{a}}$ & $3.143 \pm 0.036^{\mathrm{b}}$ \\
\hline
\end{tabular}

Values with superscripts $a, b$ differ significantly $(P<0.05)$ in a row

cells/ml were considered as healthy control.

Measurement of blood antioxidant parameters and lipid peroxides: The blood samples were collected from each affected animal in centrifuge tube containing anticoagulant. After centrifugation at 3000 rpm for $10 \mathrm{~min}$, the plasma and buffy coat were removed to harvest the red blood cells (RBC). Part of RBC pellet was diluted with chilled distilled water in $1: 10$ for the preparation of $10 \%$ stock hemolysate which was used for the estimation of SOD, CAT activities and lipid peroxidation (LPO) and rest of the $\mathrm{RBC}$ pellet was diluted with chilled normal saline in 1:1 to get $50 \%$ RBC suspension for GSH estimation. SOD and CAT activities were measured as per Madesh and Balasubramanian, [11] and Bergmeyer [12] respectively. Reduced glutathione was measured by dithio-bis-2 nitro benzoic acid (DTNB) method [13]. Lipid peroxidation was measured in terms of malondialdehyde (MDA) production as per Placer $e t$ al. [14].

Statistical analysis: Data were analyzed by one-way analysis of variance (ANOVA) using statistical software package SPSS 16.0. The comparison between values was established at level of significance, $P<0.05$.

\section{Results}

Mean CMT point score and SCC recorded in milk of healthy lactating cows were $0.00 \pm 0.00$ and $1.87 \pm$ $0.06 \times 10^{5}$ per $\mathrm{ml}$ respectively. Mean CMT point score and SCC recorded in milk of mastitic cows were 3.67 \pm 0.13 and $83.12 \pm 1.17 \times 10^{5}$ per $\mathrm{ml}$ respectively. Out of total 12 cases of clinical mastitis, 7 (58.33\%) were found positive for Streptococcus agalactiae, 2 (16.66 $\%$ ) for Micrococci, 2 (16.66\%) for Coliform and 1 $(8.33 \%)$ showed no bacterial growth on culture media. The blood antioxidant profile and lipid peroxides in dairy cows with clinical mastitis are depicted in table 1 . There was observed a significant $(P<0.05)$ decrease in blood SOD, CAT activities and GSH concentration along with a significant $(P<0.05)$ increase in erythrocytic lipid peroxides in terms of malondialdehyde production in mastitic cows.

\section{Discussion}

Mean CMT point score and SCC recorded in milk of mastitic cows correlate with clinical mastitis [9]. The present study revealed the predominance of Streptococcus agalactiae as cause of clinical mastitis in dairy cows which is a highly contagious obligate organism of the bovine mammary gland causing a lowgrade, persistent type of infection and does not have high self-healing rate $[15,16]$. Therefore, its therapeutic management by antibiotics and other protective compounds is strongly recommended.

Superoxide dismutase (SOD), a copper-zinc containing enzymatic antioxidant localized in the cytoplasm of eukaryotic cells, catalyze the dismutation of superoxide radicals to hydrogen peroxide $\left(\mathrm{H}_{2} \mathrm{O}_{2}\right)$ which can be removed by the activity of the catalase and glutathione peroxidase [17]. The present study revealed a significant decrease in SOD activity in mastitic cows which might be related with low level of zinc in blood from cows with mastitis [6]. A significant decrease in catalase activity was also observed which was similar to the finding observed by Sharma et al. [18] in bovine staphylococcal mastitis. The protective effect of catalase has been demonstrated in bovine neutrophil-induced model of mammary cell damage [19]. Decrease in enzymatic antioxidant activities might be attributed to increased consumption to counteract reactive oxygen species produced from inflamed gland, suggesting a compromise in antioxidant defense of the body.

Glutathione, a thiol-containing tripeptide, in its reduced form $(\mathrm{GSH})$ is present in living cells at high concentrations [17]. Upon reaction with reactive oxygen species, it gets oxidized to glutathione radical which can be regenerated to its reduced form by glutathione reductase $[1,17]$. The present study revealed a significant decrease in GSH concentration in mastitic cows which may be due to conversion of reduced form to oxidized form (GSSH) by excessive production of reactive oxygen species from inflamed gland. On contrary, an enhanced GSH concentration in plasma has been demonstrated in cows with mastitis by Kizil et al. [7] with the explanation that there might be enhanced activities of GSH dependent enzymes leading to intense regeneration of reduced glutathione (GSH) from the oxidized form (GSSH).

The determination of lipid peroxidation status is among the most widely used methods for determination of the oxidative stress [17]. Lipids, mainly phospholipids, containing polyunsaturated fatty acids are important constituents of the lipid bilayer of the cellular membrane and are easily oxidized [20] leading to the creation of lipid peroxides which are decomposed to aldehydes like malondialdehyde (MDA), detected by thiobarbituric acid [17]. The present study revealed a significant increase in erythrocytic MDA production 
in the cows with clinical mastitis as compared to healthy control which was similar to finding by Ranjan et al. [6]. Also an enhanced plasma MDA concentration has been documented in cows with clinical mastitis by Kizil et al. [7]. This might be due to the excessive reactive oxygen species production such as hydroxyl radicals by activated neutrophils [19] from the clinically inflamed mammary gland causing peroxidative damage to membranes.

\section{Conclusion}

It is concluded that there is a compromise in antioxidant defense of the body in dairy cows with clinical mastitis which may be due to excessive reactive oxygen species production from the clinically inflamed mammary gland, causing the oxidative stress and resultant damage, therefore, necessitating the use of antioxidants and other protective compounds along with conventional therapy in ameliorating damage to secretory cells and thus reducing subsequent milk loss.

\section{Authors' contribution}

RJ carried out the present investigation under the guidance of UD. VKG helped in collection of samples at Cattle and Buffalo farm, LPM Section, IVRI. RR helped in bacteriological examination of milk for confirmation of intramammary infection. RJ and UD analyzed the data, drafted and revised the manuscript. All authors read and approved the final manuscript.

\section{Acknowledgements}

The authors are highly grateful to Director, Indian Veterinary Research Institute, Izatnagar for providing the necessary facilities. Financial assistance from Indian Council of Agricultural Research provided to first author in form of Junior Research Fellowship is also thankfully acknowledged.

\section{Competing interests}

Authors declare that they have no competing interest.

\section{References}

1. Halliwell, B. and Gutteridege, J.M.C. (2007) Free Radicals in Biology and Medicine, 4th ed. Oxford University Press, Midsomer Norton, Avon, England.

2. Sordillo, L.M. and Aitken, S.L. (2009) Impact of oxidative stress on the health and immune function of dairy cattle. Vet. Immunol. Immunopathol. 128: 104-109.
3. Lykkesfeldt, J. and Svendsen, O. (2007) Oxidants and antioxidants in disease: Oxidative stress in farm animals. Vet. J. $173502-511$.

4. Celi, P. (2010) The role of oxidative stress in small ruminants' health and production. R. Bras. Zootec. 39: 348363.

5. Zhao, X. and Lacasse, P. (2008) Mammary tissue damage during bovine mastitis: Causes and control. J. Anim. Sci. 86(1): 57-65.

6. Ranjan, R., Swarup, D., Naresh, R. and Patra, R.C. (2005) Enhanced erythrocytic lipid peroxides and reduced plasma ascorbic acid, and alteration in blood trace elements level in dairy cows with mastitis. Vet. Res. Commun. 29:27-34.

7. Kizil, O., Akar, Y., Saat, N., Kizil, M. and Yuksel, M. (2007) The plasma lipid peroxidation intensity (MDA) and chainbreaking antioxidant concentrations in the cows with clinic or subclinic mastitis. Revue Méd. Vét. 158(11): 529-533.

8. Schalm, O.W. and Noorlander, D.O. (1957) Experiments and observations leading to development of the California mastitis test. J. Am. Vet. Med. Assoc. 130: 199-204.

9. Schlam, O.W., Carrol, E.J. and Jain, N.C. (1971) Bovine mastitis Lea and Febiger, Philladelphia, pp. 128-129.

10. Quinn, P.J., Carter, M.E., Markey, B. and Carter, G.R. (2004) Clinical Veterinary Microbiology, Mosby, Elsevier Limited, Philadelphia, USA.

11. Madesh, M. and Balasubramanian, K. A. (1998) Microtiter plate assay for superoxide dismutase using MTT reduction by superoxide. Indian J. Biochem. Biophys. 35(3):184-8.

12. Bergmeyer, H.U. (1983) U.V. Method of catalase assay. In "Methods of Enzymatic Analysis" Vol: 3, Weinheim. Deer field Beach, Florida, p. 273.

13. Prins and Loos. (1969) Biochemical Methods in Red Cell Genetics. Academic Press. 127-129.

14. Placers, Z. A., Cushman, L. and Johnson, B. (1966) Estimation of product of lipid peroxidation (malondialdehyde) in biochemical system. Anal. Biochem. 16:3359-64.

15. Keefe, G.P. (1997) Streptococcus agalactiae mastitis: A review. Can. Vet. J. 38: 429-437.

16. Elias, A.O., Cortez, A., Brandão, P.E., da Silva R.C. and Langoni, H. (2012) Molecular detection of Streptococcus agalactiae in bovine raw milk samples obtained directly from bulk tanks. Res. Vet. Sc. 93(1): 34-38.

17. Kohen, R. and Nyska, A. (2002) Oxidation of biological systems: oxidative stress phenomena, antioxidants, redox reactions, and methods for their quantification. Toxicol. Pathol. 30: 620-650.

18. Sharma, N., Mukherjee, R., Ingale, S.L. and Jadhav, R.K. (2010) Therapeutic and anti-oxidant activity of vitamin E and selenium in bovine Staphylococcal mastitis. Indian $J$. Vet. Res. 19(1): 25-31.

19. Boulanger, V., Zhao, X. and Lacasse, P. (2002) Protective Effect of Melatonin and Catalase in Bovine Neutrophilinduced Model of Mammary Cell Damage. J. Dairy Sci. 85(3): 562-569.

20. Catalá, A. (2010) A synopsis of the process of lipid peroxidation since the discovery of the essential fatty acid. Biochem. Biophys. Res. Commun. 399: 318-323. 